\title{
Analysis of the Law of Joint Deformation for Grouted Mortise-Tenon Joint
}

\author{
Xiuren Yang $\mathbb{D}^{1,2}$ Fang Lin $\mathbb{D}^{1,2}$ and Meiqun Huang ${ }^{1,2}$ \\ ${ }^{1}$ Beijing Urban Construction Design and Development Group Co., Ltd.,, Beijing 100037, China \\ ${ }^{2}$ National Engineering Laboratory for Green \& Safe Construction Technology in Urban Rail Transit, Beijing 100037, China
}

Correspondence should be addressed to Xiuren Yang; yangxr@bjucd.com and Fang Lin; felyo@foxmail.com

Received 22 December 2021; Revised 17 January 2022; Accepted 19 January 2022; Published 31 January 2022

Academic Editor: Paolo S. Valvo

Copyright (c) 2022 Xiuren Yang et al. This is an open access article distributed under the Creative Commons Attribution License, which permits unrestricted use, distribution, and reproduction in any medium, provided the original work is properly cited.

\begin{abstract}
This paper analyzes the law of joint deformation of grouted mortise-tenon joint with $1: 1$ prototype test in key working direction types under 38 working conditions of different joint types, tenon lengths, grouting ranges, grouting materials, and loading combinations for the prefabricated metro station. The deformation performance of the joint has also been compared. In addition, finite element models have been built, and the joint deformation stages are discussed. The influences on the law of joint deformation of different influencing factors have been discovered. The deformation development stages and the main deformation laws of each stage of the joints have also been obtained. Moreover, this paper also compares and analyzes the field test results and experimental results. The monitoring results show that the safety margin of joint deformation is sufficient during the whole construction process from the assembly to the completion of the station. The research results have great values for the joint design and calculation for the prefabricated metro station structure.
\end{abstract}

\section{Introduction}

The municipal underground projects, such as urban rail transit, are typically of linear and long box frame structure or tunnel structure, characterized by a simple type and a high degree of standardization. The use of prefabricated construction technology will contribute to better technical, economic, and social benefits. As the most widely used prefabricated underground structure in the world, the shield tunnel has a history of over 100 years. Since the 1970s, the countries of the former Soviet Union had adopted the prefabricated construction technology successively in the metro stations and interval works that were constructed with the cut and cover method and the mining method to solve the problems encountered during winter construction [1-4].

In 2018, the Changchun Metro Line 2, as one of the first batch of cut-and-cover prefabricated metro stations in China, was successfully completed and opened to the public, and this type of cut-and-cover prefabricated metro station was promoted and used in the subsequent projects as well as other metro projects in Qingdao, Shenzhen, and other cities.
Up to now, there are 30 either completed or under construction prefabricated metro stations in China $[5,6]$.

The prefabrication technology provides metro stations with a brand-new industrialized construction mode, having significant advantages in terms of engineering quality, efficiency and speed of construction, labour saving, environmental protection, and low carbon. This technology will not only help to solve the winter construction problems in areas with severe cold but also be applied to the engineering construction in other areas. This technology is extensively used. In addition to cut-and-cover stations in the urban rail transit, this technology is suitable for the following underground structures: cut-and-cover tunnels, entrance and exit passages and airways; it is also applicable in the cut-andcover underground projects like road tunnels, utility tunnels, sidewalks, etc., of the municipal works.

The prefabricated station of Changchun Metro is designed with the underground two-deck structure of longspan single-arch tunnel, as shown in Figure 1. The structure is longitudinally split into several $2 \mathrm{~m}$-wide standard structure rings, and each structural ring is subdivided into 7 


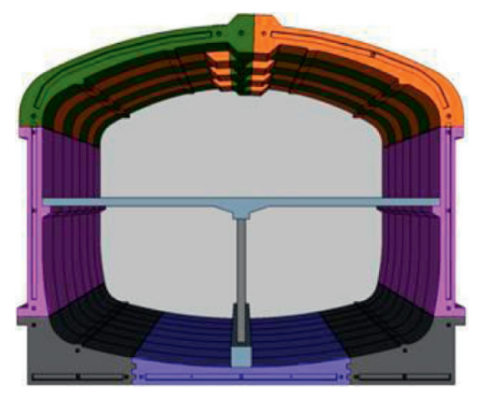

(a)

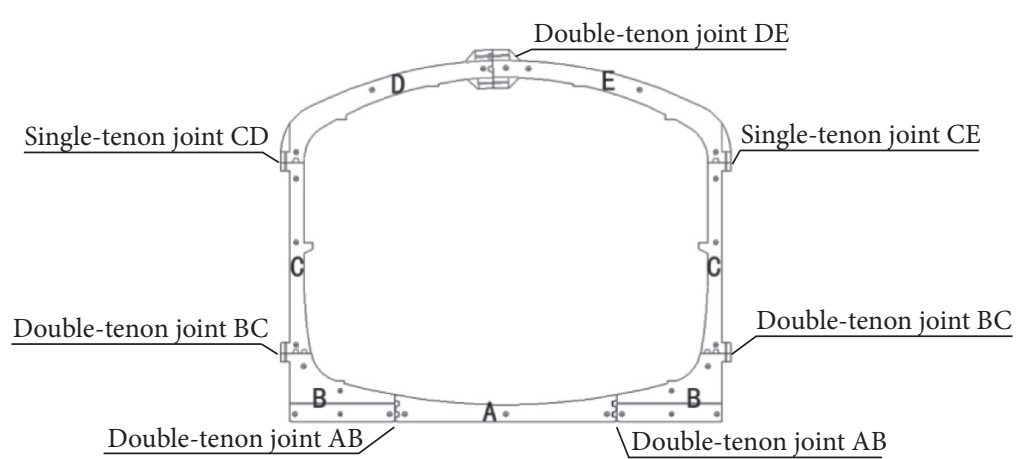

(b)

Figure 1: Cross section of prefabricated station structure on Changchun metro. (a) Prefabricated station structure. (b) Cross section.

standard components, and all components are prefabricated in a factory, then delivered to the site and finally assembled in the cut-and-cover foundation pit to form the structure; dry-fit mortise-tenon joints are used circumferentially and longitudinally in precast components for quick and reliable connection, sealing and waterproofing measures are taken for joints, and no external waterproof layer is required to be provided for the outside of the station structure.

A joint is the most critical element of the prefabricated structure system, and the joint type is closely linked to the load-carrying capacity, construction technology, and waterproof performance of the prefabricated structure [7-12]. The frequently used prefabricated structure joints are as follows: rigid joints used in the ground prefabricated structure, e.g., wet-fit reinforced concrete continuous joint; flexible joints frequently used in the shield tunnel, e.g., plate joints, mortise-tenon joints, ball joints, joints with various curved surfaces, and other variable-stiffness joints. For grouted mortise-tenon joints, the mortise-tenon connection is used and grout is poured in joints to close joints and reinforce the reliability and deformation resistance of connection, so this type of joint is a typical variable-stiffness joint that has significant advantages in terms of mechanical characteristics, seismic resistance, waterproof performance, and convenience.

For the structures of several types of grouted mortisetenon joints used in the prefabricated station of Changchun Metro, refer to Figure 2. With regard to the structure of the prefabricated metro station using grouted mortise-tenon joints, the relevant rotational deformation of the joint between two precast components will result in the redistribution of internal force of the structure system and also be the important factor having a direct impact on the joint loadbearing capacity $[13,14]$. As the load effect varies, the change law of relevant rotational deformation of joints plays an important role in, and is of great significance to, the judgment of the bearing capacity and bending strength of joints $[15,16]$.

In the past, the research on the joints of prefabricated underground structure focused on the plain joints used in the shield tunnel [17-20]. The structure of the grouted mortise-tenon joints used in the prefabricated structure of metro station is complicated and the force applied to them is special, but there was very little research on these joints before. A range of 1:1 prototype tests of mechanical properties in this paper, which were based on grouted mortise-tenon joints, research and analyze the joint deformation law of grouted mortise-tenon joints in varied cases involving different grouting materials, different ranges of grouting, different tenon lengths, different types, different axial forces, etc.

\section{Experimental Cases}

With regard to grouted mortise-tenon joint, this paper utilizes the step-by-step cyclic loading method to conduct joint loading tests [21] for different grouting materials, different ranges of grouting, different tenon lengths, and different structural types under varied axial forces and bending moments. The specific experimental cases are shown in Table 1, and the size of C50 concrete test specimens is illustrated in Figure 3. Observation points are separately distributed on the front side, tension side (bottom), and compression side (top) of a joint, and the pull rope and push rod displacement sensors are used to measure joint deformation, and the distribution of displacement meters is illustrated in Figure 4. For the variation value of the tension side in the direction of tension, the joint deformation is a "+" value; for the variation value of the compression side in the direction of compression, the joint deformation is a "-" value. The initial joint width is $5 \mathrm{~mm}$, and the deformation refers to the variation value relative to the initial joint width.[22].

\section{Comparative Study of the Law of Joint Deformation in Different Cases}

\subsection{Law of Joint Deformation with Different Grouting Materials}

(1) Based on the test results, the development law of joint deformation of the same type of joint using different grouting materials at different bending moments under the same axial force and the same range of grouting is shown in Figure 5, marking the resistance moment $\left(M_{R}\right)$ (which refers to the 


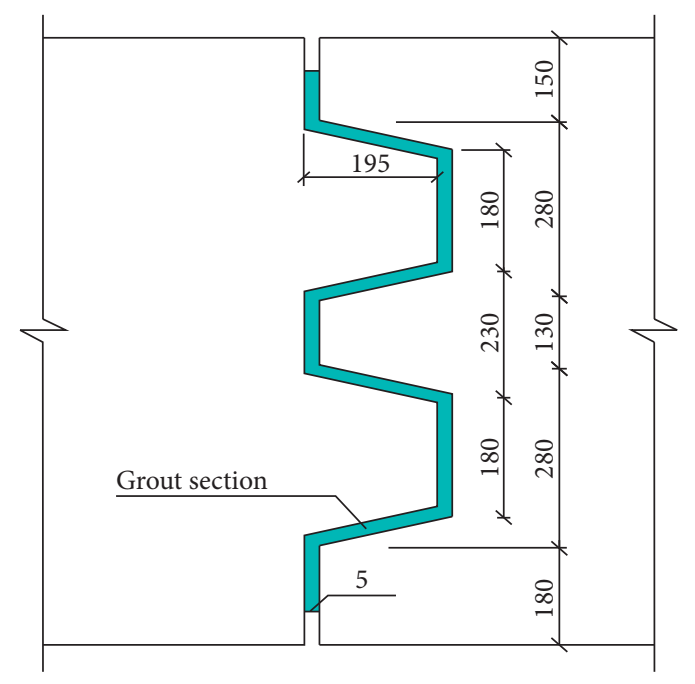

(a)

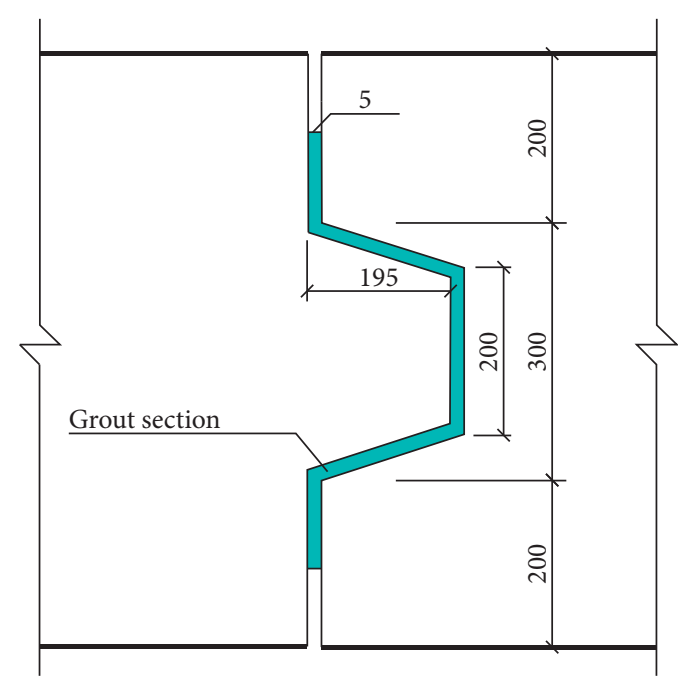

(b)

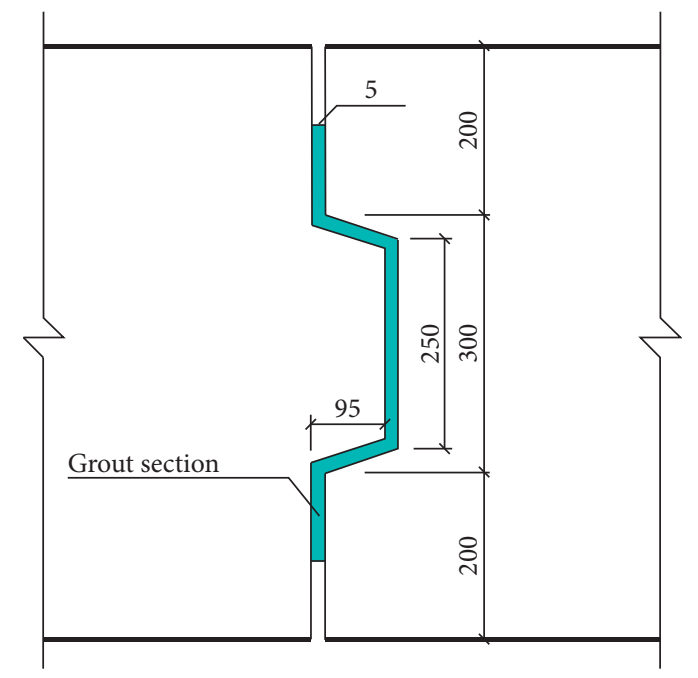

(c)

Figure 2: Construction structure of grouted mortise-tenon joint (unit: mm). (a) Double-tenon joint, (b) long single-tenon joint, (c) short single-tenon joint.

TABLE 1: Experimental cases.

\begin{tabular}{|c|c|c|}
\hline \multirow{4}{*}{$\begin{array}{l}\text { Experimental } \\
\text { cases }\end{array}$} & Different axial forces & $\begin{array}{l}\text { Single-tenon joint: } 500 \mathrm{kN}, 1,600 \mathrm{kN}, \& 2,000 \mathrm{kN} \\
\text { Double-tenon joint: } 500 \mathrm{kN}, 1,000 \mathrm{kN}, \& 1,250 \mathrm{kN}\end{array}$ \\
\hline & $\begin{array}{l}\text { Different ranges of } \\
\text { grouting }\end{array}$ & $\begin{array}{c}\text { a (tenon \& mortise only), b ( } 60 \mathrm{~mm} \text { externally expanded from tenon \& mortise), c (100 mm } \\
\text { externally expanded from tenon \& mortise) }\end{array}$ \\
\hline & $\begin{array}{l}\text { Different grouting } \\
\text { materials }\end{array}$ & Modified epoxy resin, pure epoxy resin, cement-based material, no grouting \\
\hline & $\begin{array}{r}\text { Differer } \\
\text { len }\end{array}$ & ngth: $195 \mathrm{~mm}$ \\
\hline Conten & $\begin{array}{l}\text { Different types } \\
\text { collected in tests }\end{array}$ & $\begin{array}{r}\text { Double-tenon joint (is there an } \\
\text { Deformation }\end{array}$ \\
\hline
\end{tabular}

moment formed by effective contact area of joints to resist the bending moment action, with the effect of axial force) [12] in each comparative case. It can be seen from the diagrams that the variation curve of joint deformation mainly consists of 4 stages: linear variation stage $\longrightarrow$ quasi-linear variation $\longrightarrow$ nonlinear variation stage $\longrightarrow$ stage of sharp increase in deformation until damage to a test specimen (instability damage stage). After the bending moment exceeds the resistance moment $\left(M_{R}\right)$, the nonlinear stage will start very soon. 

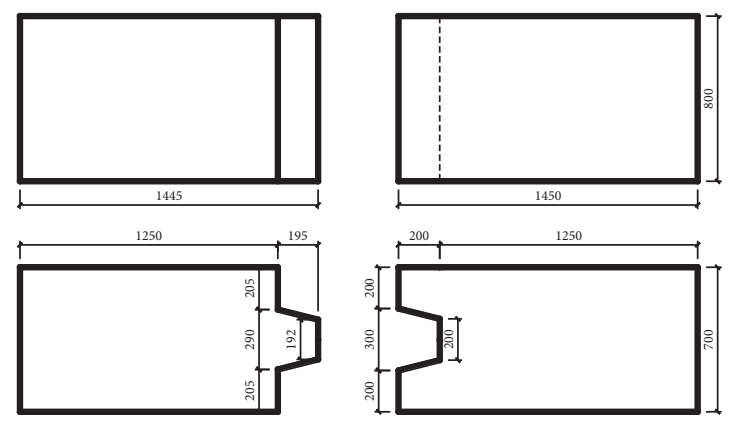

(a)
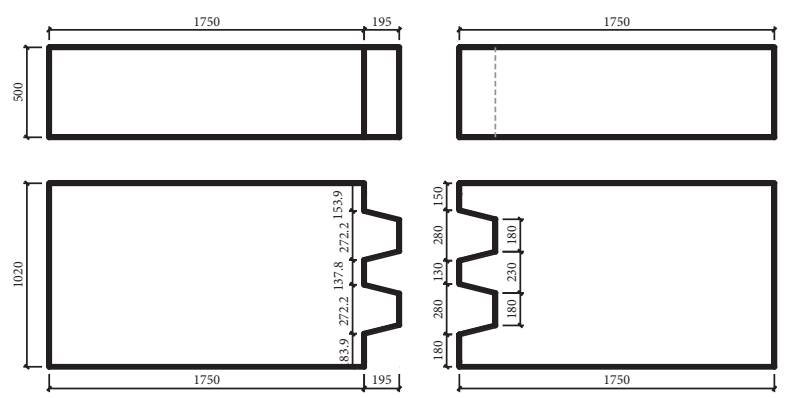

(c)
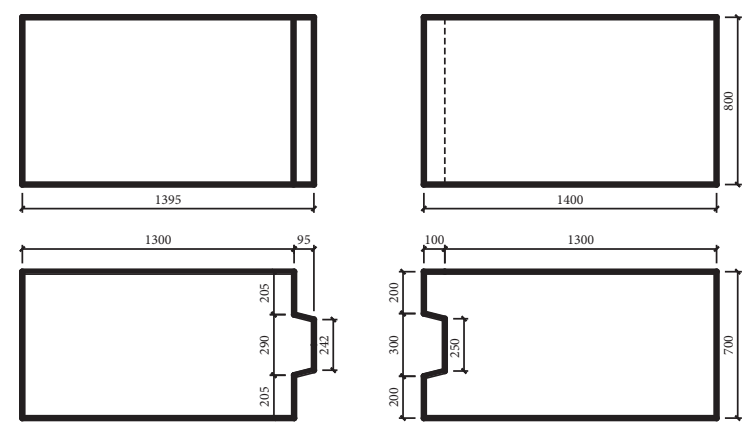

(b)
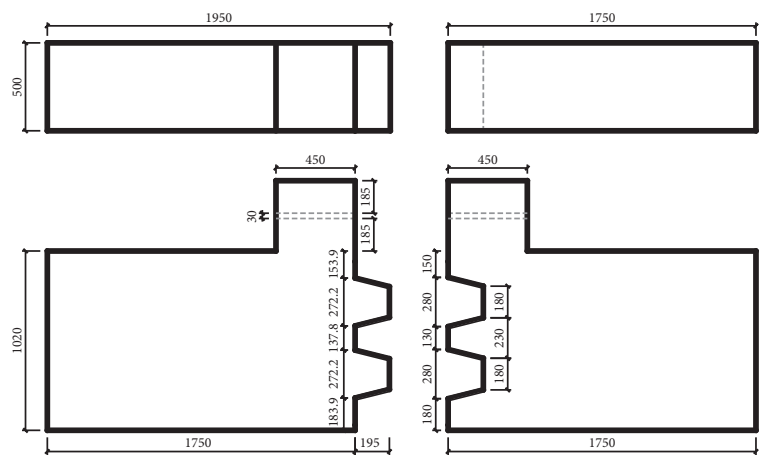

(d)

FiguRE 3: Specimen size of grouted mortise-tenon joint. (a) Long single-tenon joint, (b) Short single-tenon joint, (c) Double-tenon joint, (d) Double-tenon joint with auxiliary pretightening device.

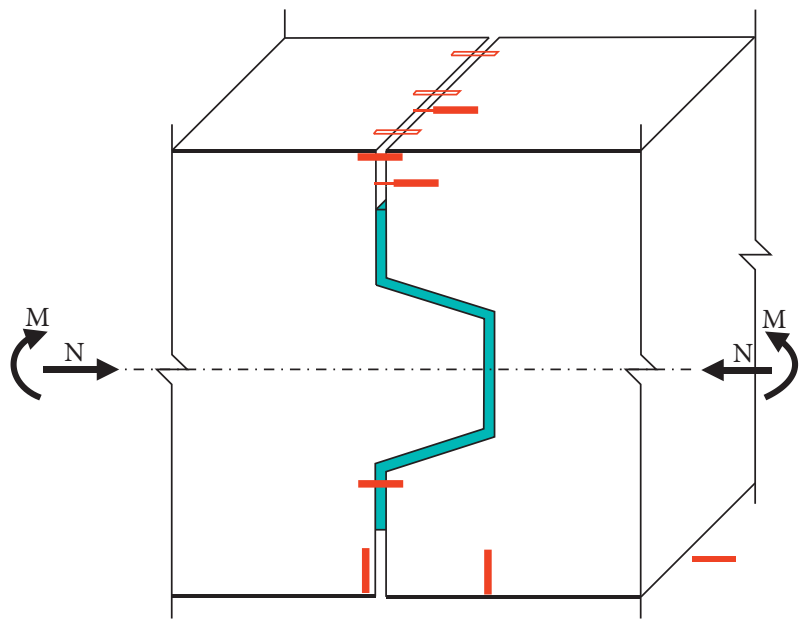

Pull rope displacement meter

_ Push rod displacement meter

FIGURE 4: Location of displacement meters.

(2) All other things being equal, the joint deformation curve of the test specimen being poured with pure epoxy resin grout is relatively similar to that with modified epoxy resin grout (refer to Figure 5(a)).

(3) When cement-based grout and modified epoxy resin grout are poured, their deformation curves are similar within $3 \mathrm{~mm}$ of the deformation on the joint tension side (Figure 5(b)), but the ultimate failure forms of two test specimens are completely different. The cement-based test specimen disengages along the joint base side, while the joint base side of the modified epoxy resin test specimen is not pulled apart and the concrete cover along the joint is pulled apart (Figure 6).

(4) For the test specimens with no grouting (Figure 5(c)), the ultimate joint deformation on the tension side is quite large and is more than $30 \mathrm{~mm}$, and the deformation curve of any test specimen with no grouting changes greatly, regardless of whether it is the compression or tension side. It can be seen from the diagram that, compared with the grouted joint, the joint with no grouting enters the rapid increase stage earlier under the same axial force, and after the grouted joint exceeds the resistance moment $\left(M_{R}\right)$, it will experience the nonlinear variation stage before entering the rapid increase stage.

(5) The analysis of the comparison between the development law of joint deformation and the development process of joint crack (as shown in Figures 5(b) and 7) indicates that the appearance and development stages of cracks correspond exactly to the inflection point of linear stage and quasi-linear stage of the joint deformation on the tension side and the inflection point of quasi-linear stage and nonlinear stage, the tenon crack penetration stage corresponds exactly to the inflection point of nonlinear stage and instability damage stage of joint deformation, and 


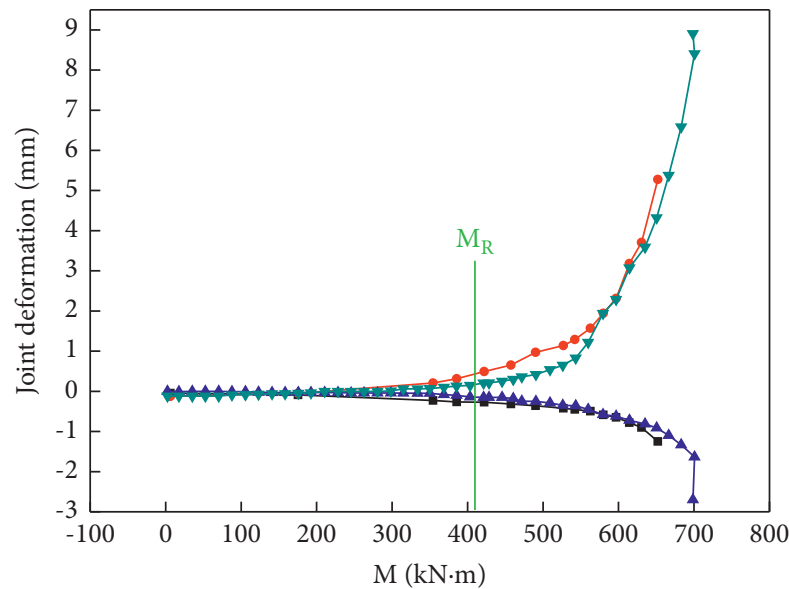

$2000 \mathrm{kN}$

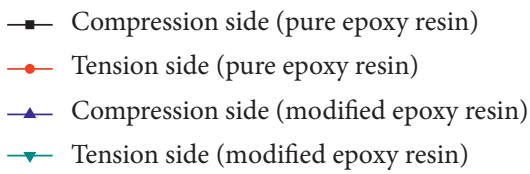

(a)

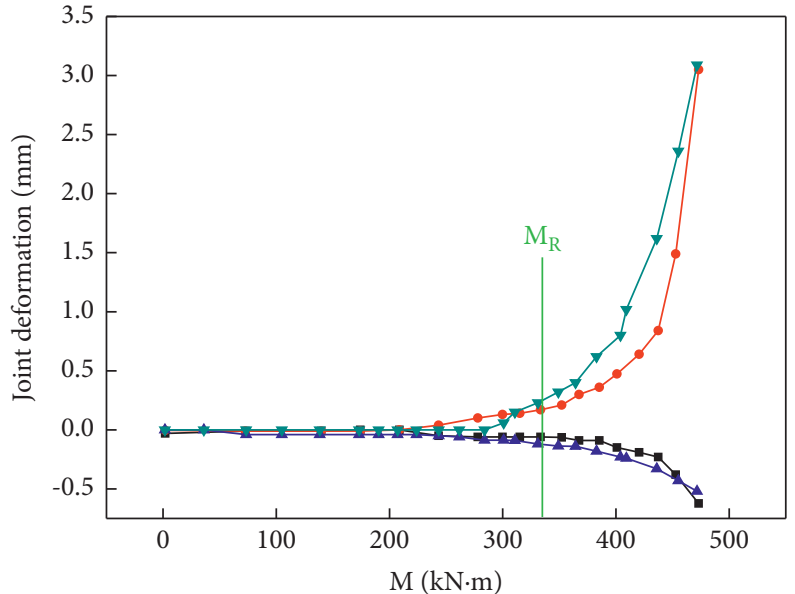

$1600 \mathrm{kN}$

$\rightarrow$ Compression side (modified epoxy resin)

$\rightarrow$ Tension side (modified epoxy resin)

$\_$Compression side (cement-based material)

$\rightarrow$ Tension side (cement-based material)

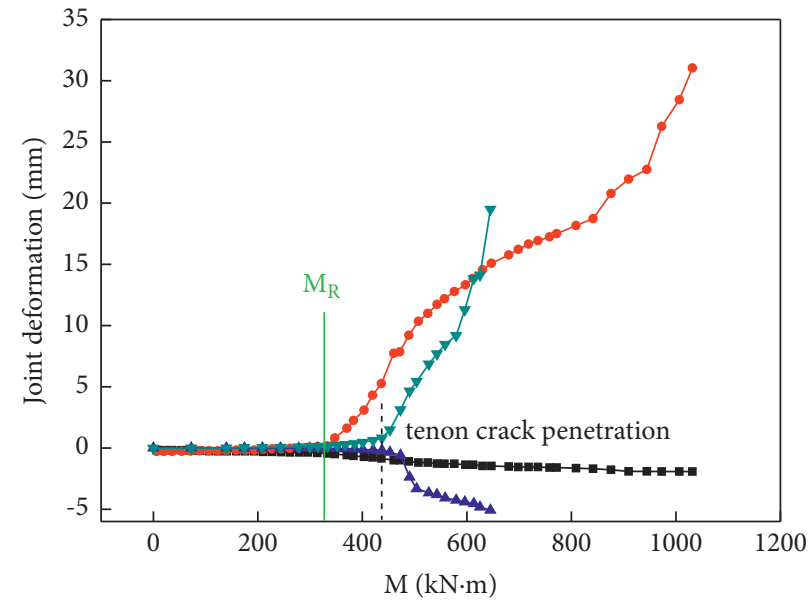

$1600 \mathrm{kN}$

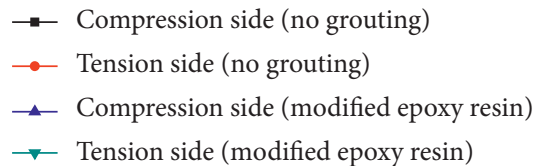

(c)

Figure 5: Comparison of joint deformation development for different grouting materials (long single-tenon joint). (a) Pure and modified epoxy resin, (b) modified epoxy resin and cement-based material, (c) modified epoxy resin and no grouting material.

the structural damage and bearing capacity loss stage corresponds exactly to the sudden change stage of joint deformation.

To sum up, from the perspective of the development law of joint deformation, the difference in grouting materials will have little impact on joint deformation, the deformation curves are relatively similar, and the difference in the pouring between cement-based material and epoxy resin lies in the final failure form; however, whether the joint is grouted or not has a great impact on joint deformation, indicating that grouting plays a very important role in restricting deformation.

3.2. Law of Joint Deformation with Different Grouting Ranges. Under the same axial force, the law of joint deformation with different grouting ranges is shown in Figure 8, showing that the joint deformation with grouting range $b$ will be far less than that with grouting range a. The occurrence of tenon 


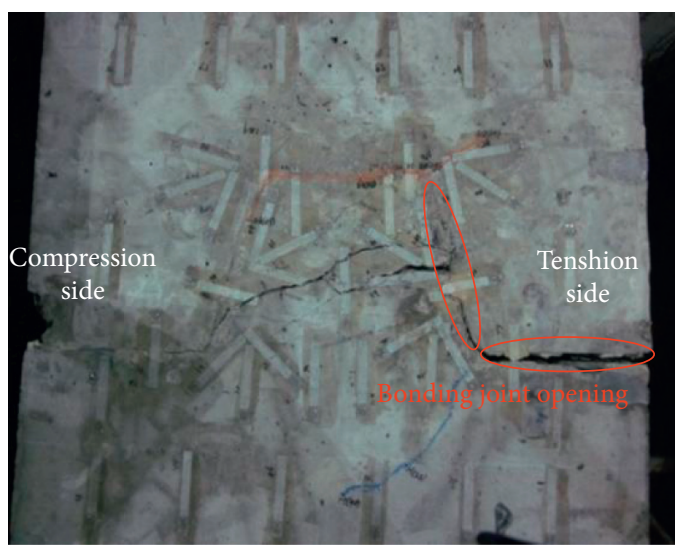

(a)

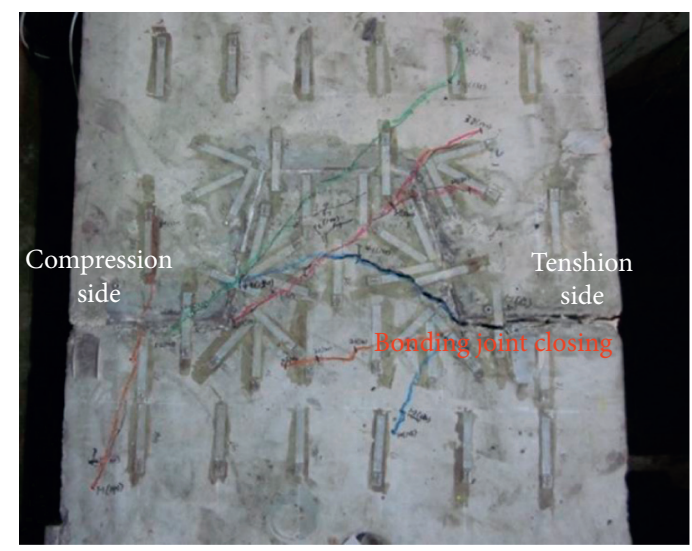

(b)

FIGURE 6: Failure modes of joints with modified epoxy resin and cement-based grouting materials. (a) Cement-based grouting materials cracking in seam surface, (b) modified epoxy resin cracking in the concrete cover.

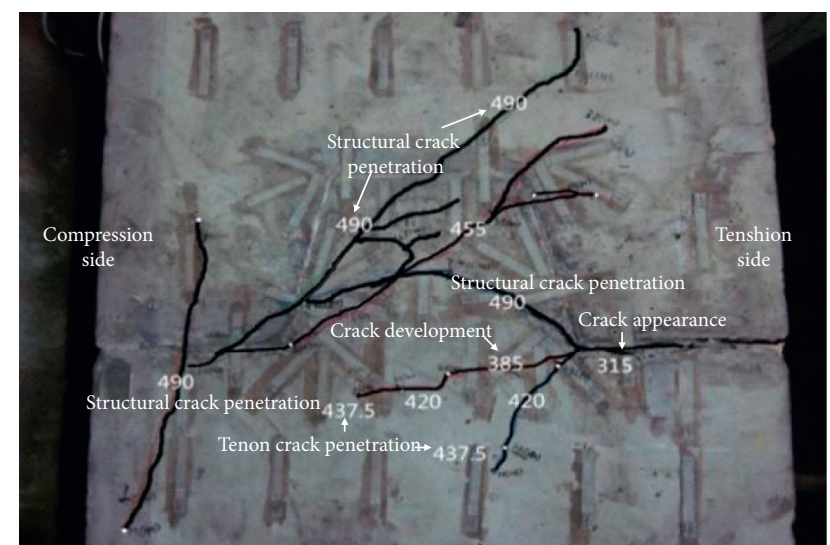

Figure 7: Crack development of specimen with modified epoxy resin.

crack penetration and structural crack penetration corresponding to the inflection point of the deformation curve with grouting range a is earlier than that with grouting range $\mathrm{b}$, especially the tenon crack penetration stage, and the occurrence of these stages with grouting range a is far earlier than that with grouting range $b$ and the deformation at the inflection point is greater than that with grouting range $b$. After structural crack penetration, the deformation on both sides of grouting range $b$ increases quickly.

Compared with grouting range $a$, grouting range $b$ has $a$ larger contact area, so its resistance moment is large; in cases having both these two grouting ranges, the joint deformation is very small at the resistance moment, and the deformation of grouting range a is slightly larger than that of grouting range b; after the load exceeds the resistance moment, the growth rate of the curve becomes faster, and the increase rate of grouting range $a$ is significantly more than that of grouting range $b$.

Thus, an increase in the grouting range enhances the resistance moment, allowing the limitation and closing of the grouting stage to be fully displayed and contributing to the restriction to the tension of joints.

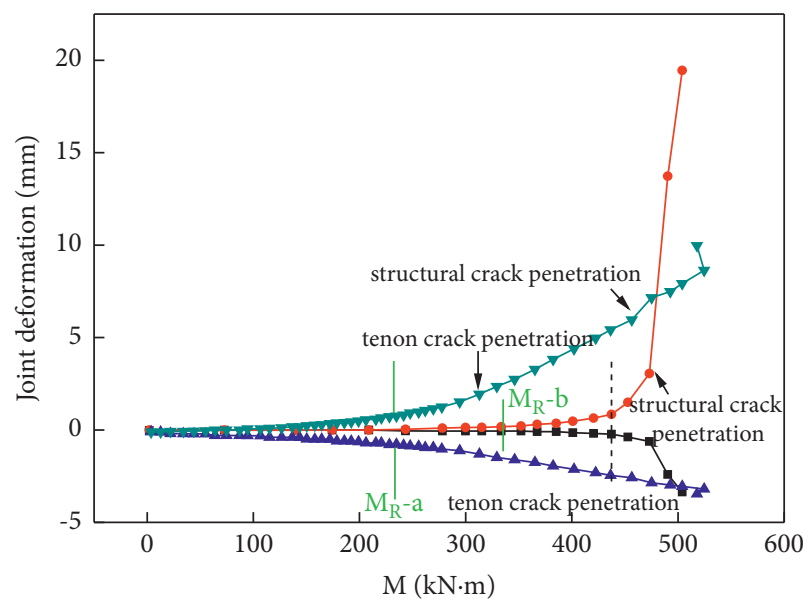

$1600 \mathrm{kN}$

$\rightarrow-$ Compression side (grout range b)

$\rightarrow$ Tension side (grout range b)

$\_$Compression side (grout range a)

$\rightarrow$ Tension side (grout range a)

FIGURE 8: Development law of joint deformation with different grouting ranges (long single-tenon joint).

3.3. Law of Joint Deformation with Different Tenon Lengths. Under the same axial force, the law of joint deformation with the same grouting range and different tenon lengths is illustrated in Figure 9, indicating that if the deformation is small, especially before the resistance moment, the deformation of long tenon and short tenon increases with an increase in the bending moment, the deformation curves are similar, and then the short-tenon test specimen is suddenly damaged, while the long tenon has the larger ultimate flexural capacity, and compared with the short tenon test specimen, the long tenon test specimen has the stage of sharp increase in deformation until damage to a test specimen. Especially, this is the case for the tension side. Long tenons are conducive for the utilization of joint bending resistance 


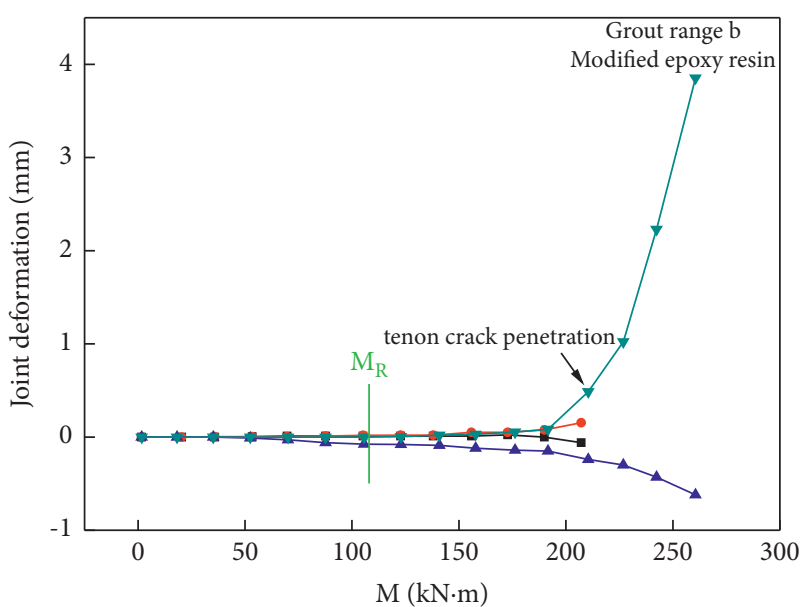

$500 \mathrm{kN}$

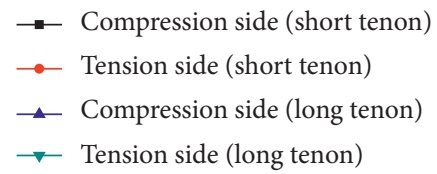

Figure 9: Development law of joint deformation with different tenon lengths.

[23] and have better bearing capacity and deformation capacity compared with short tenons.

\subsection{Law of Joint Deformation under Different Axial Force} Cases. For the joint test specimens having the same grouting range and the same grouting material, the law of joint deformation under different axial force cases is shown in Figure 10, indicating that the deformation curve experiences the stage from stable development to rapid development. As the axial force increases, the ultimate flexural capacity of joints will also increase, and after the deformation curve enters the inflection point of rapid change stage, the bending moment value will increase and the joint deformation resistance is enhanced; with the effect of the same bending moment, the smaller the axial force is, the larger is the deformation value; in different axial force cases, if the load does not exceed the resistance moment, the joint deformation will be very small, and if the load exceeds the resistance moment, the joint deformation will be significantly increased. In a word, the axial force is increased, the resistance moment is increased, and the resistance of the cross section to be utilized in the early stage is increased, so that the development of joint deformation can be effectively controlled.

The joint deformation curve of the double-tenon joint without an auxiliary pretightening device under the axial forces of $500 \mathrm{kN}, 1,000 \mathrm{kN}$ and $1,250 \mathrm{kN}$ is shown in Figure 11. For the joint without an auxiliary pretightening device, as the axial force increases, the inflection joint of the joint deformation curve moves rearward, the ultimate bearing capacity increases, the maximum deformation on both sides also increases, and the deformation on the tension side more obviously changes.

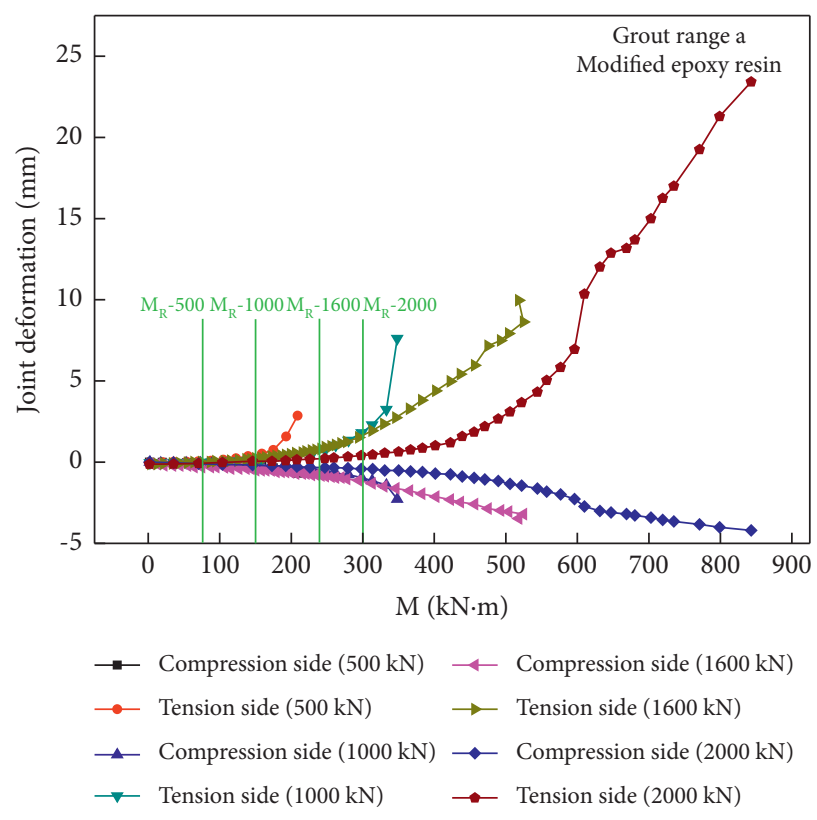

FIgURE 10: Development law of joint deformation with different axial loads (long single-tenon joint).

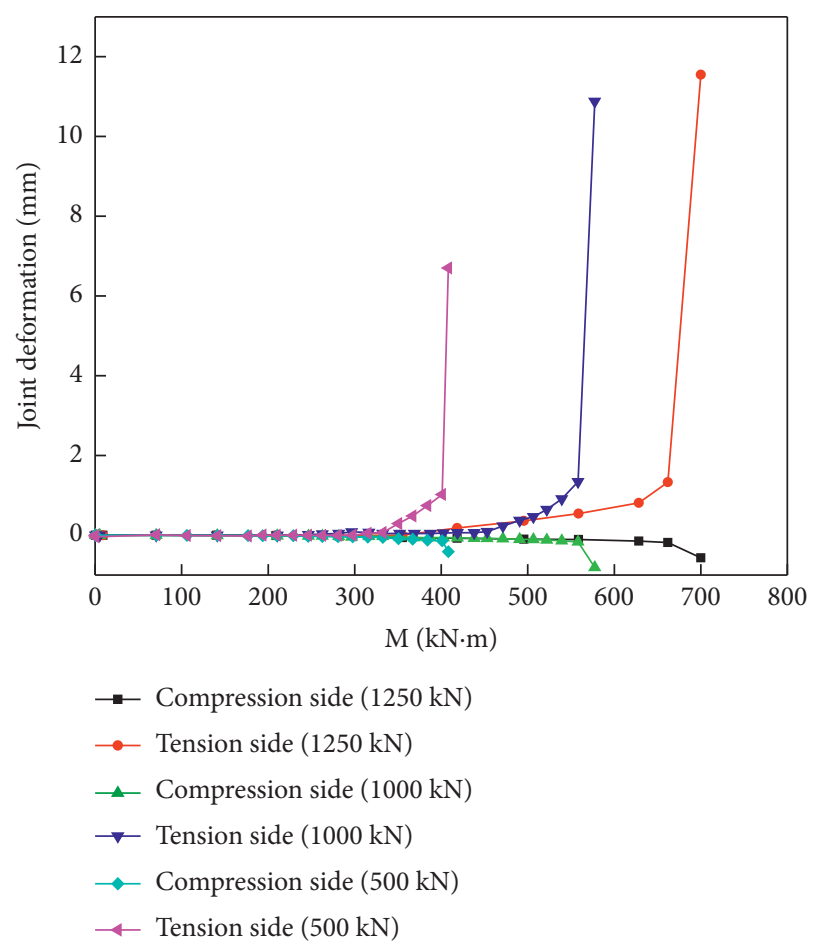

Figure 11: Deformation development of double-tenon joints without auxiliary pretightening device.

With regard to the tension side, the deformation has three inflection points: from the stage joint deformation is almost zero to the slow-changing linear stage; the slowchanging linear stage to the nonlinear stage; and from the nonlinear stage to the sudden change stage. With regard to the compression side, the first point is not obvious, and 
behind the third point, the compression side changes quickly and reaches the load bearing limit very soon. These three inflection points are close to the appearance of cracks, crack development, and the time of crack penetration between two mortises (slightly less), as shown in Figure 12.

The joint deformation curve of the double-tenon joint with an auxiliary pretightening device on the tension side under the axial forces of $500 \mathrm{kN}, 1,000 \mathrm{kN}$ and $1,250 \mathrm{kN}$ is shown in Figure 13. For the double-tenon joint with an auxiliary pretightening device on the tension side, as the axial force increases, the inflection point moves rearward, the bearing capacity increases, and the deformation trend is identical to the double-tenon joint without an auxiliary pretightening device. The differences are as follows: on the tension side, Inflection Point 1 corresponds to the time of crack appearance, and before this inflection point, the joint deformation is almost zero; the subsequent deformation increases linearly, and as the axial force increases, the slope of this stage declines; next, Inflection Point 2 appears, closing to the tenon penetration stage of the tension side. If the axial force is 0 , Inflection Point 3 will not exist. Starting from Inflection Point 2, the deformation on the tension side increases quickly and reaches the ultimate bearing capacity; under other axial forces, Inflection Point 3 will appear, closing to the stage of crack penetration between two mortises, and subsequently, the deformation is sharply increased to the damage level.

The joint deformation curve of the double-tenon joint with an auxiliary pretightening device on the compression side under the axial forces of $500 \mathrm{kN}, 1,000 \mathrm{kN}$ and $1,250 \mathrm{kN}$ is shown in Figure 14. For the double-tenon test specimen of the external additional tension device on the compression side, as the axial forces increase, the curve inflection point moves rearward; the inflection point under the axial force of $500 \mathrm{kN}$ is at the front, and the inflection point under the axial force of $1,250 \mathrm{kN}$ is slightly behind that under $1,000 \mathrm{kN}$. Different from the joint with an auxiliary pretightening device on the tension side, the joint deformation under the remaining two axial forces rises to the second inflection point slowly and linearly, then the slope increases, the curve is sharply increased to the ultimate limit state very soon, and the latter two inflection points are close to the bending moment values at the stages of crack penetration between tenon crack penetration (slightly less than it) and structural crack penetration, except that the joint deformation on the tension side under $1,250 \mathrm{kN}$ is almost zero for a very long bending moment (before $600 \mathrm{kN} \cdot \mathrm{m}$ ). Thus, for the joints with auxiliary pretightening device in the compression side, the auxiliary pretightening device is more conducive for the control of joint deformation in the early stage of loading, but in the late stage, the auxiliary pretightening device fails to function anymore, so the joints with the auxiliary pretightening device in the tension side are suddenly damaged, and the joint deformation curve is relatively steep.

3.5. Comparison and Analysis of Different Types of Joints. A comparison is made between different types of doubletenon joints under the same axial force $(1,000 \mathrm{kN})$, i.e., joints

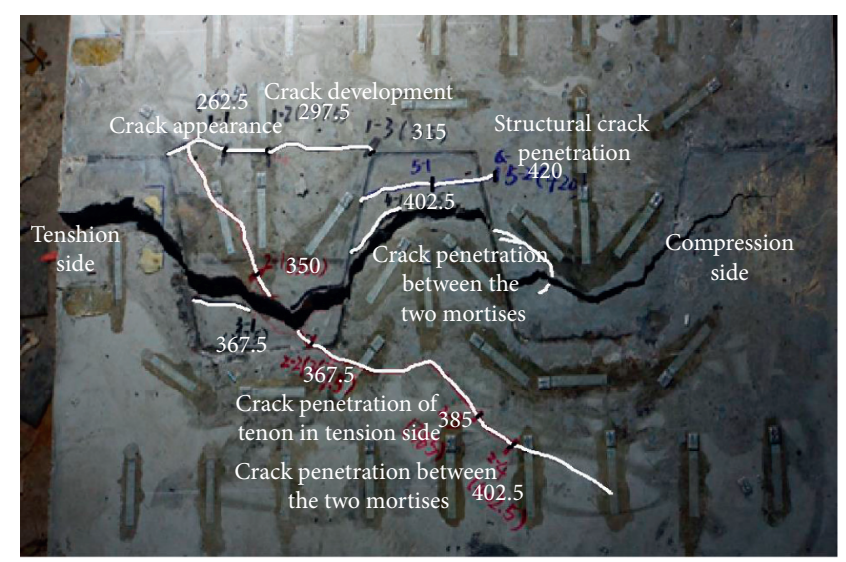

FIgURE 12: Failure modes of specimen under axial force $500 \mathrm{kN}$.

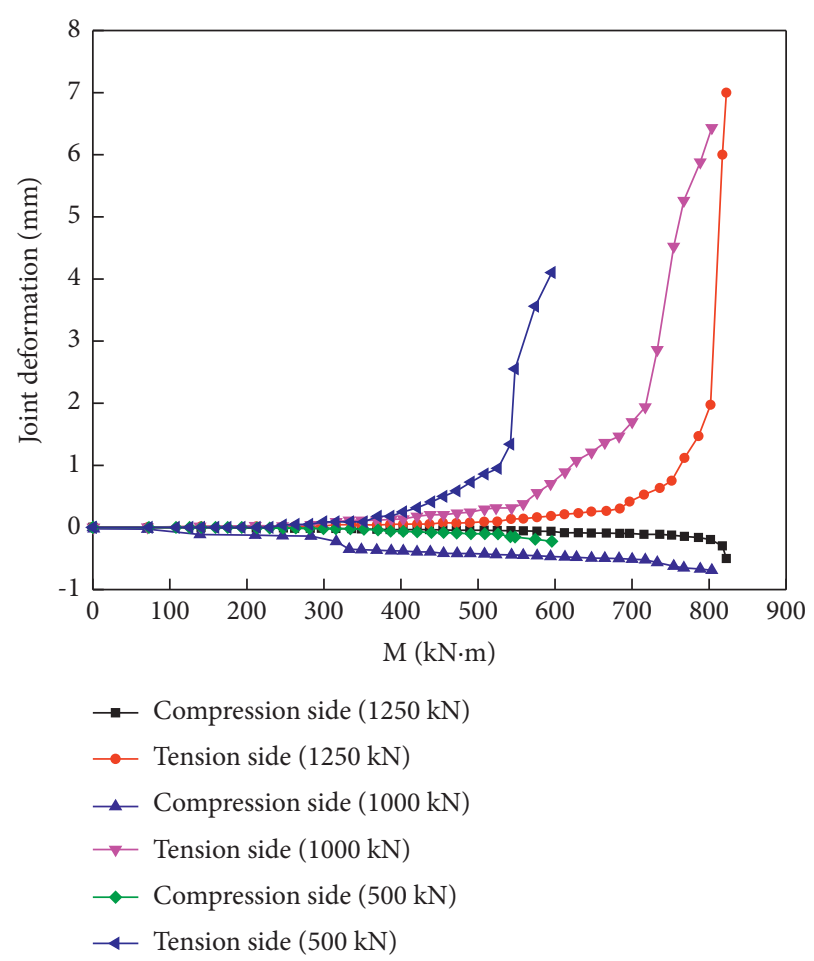

Figure 13: Deformation development of double-tenon joints with auxiliary pretightening device on the tension side.

without an auxiliary pretightening device, and joints with an auxiliary pretightening device on the tension side and the compression side, and the development trend curve of joint deformation is illustrated in Figure 15. The following can be seen from the diagram:

(1) Under the same axial force, the joint deformation curve of the joint with an auxiliary pretightening device moves rearward relative to the joint deformation curve of the joint without an auxiliary pretightening device, and the ultimate bearing capacity is increased

(2) Compared with the joint with an auxiliary pretightening device, the joint without an external 


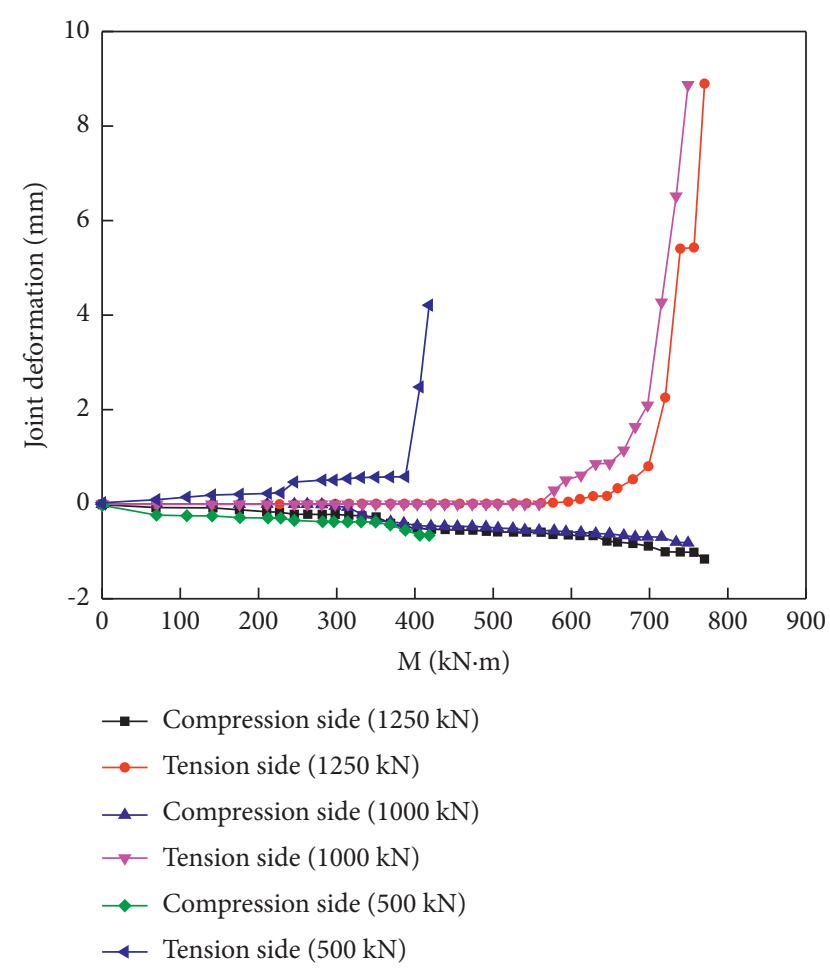

Figure 14: Deformation development of double-tenon joints with auxiliary pretightening device on the compression side.

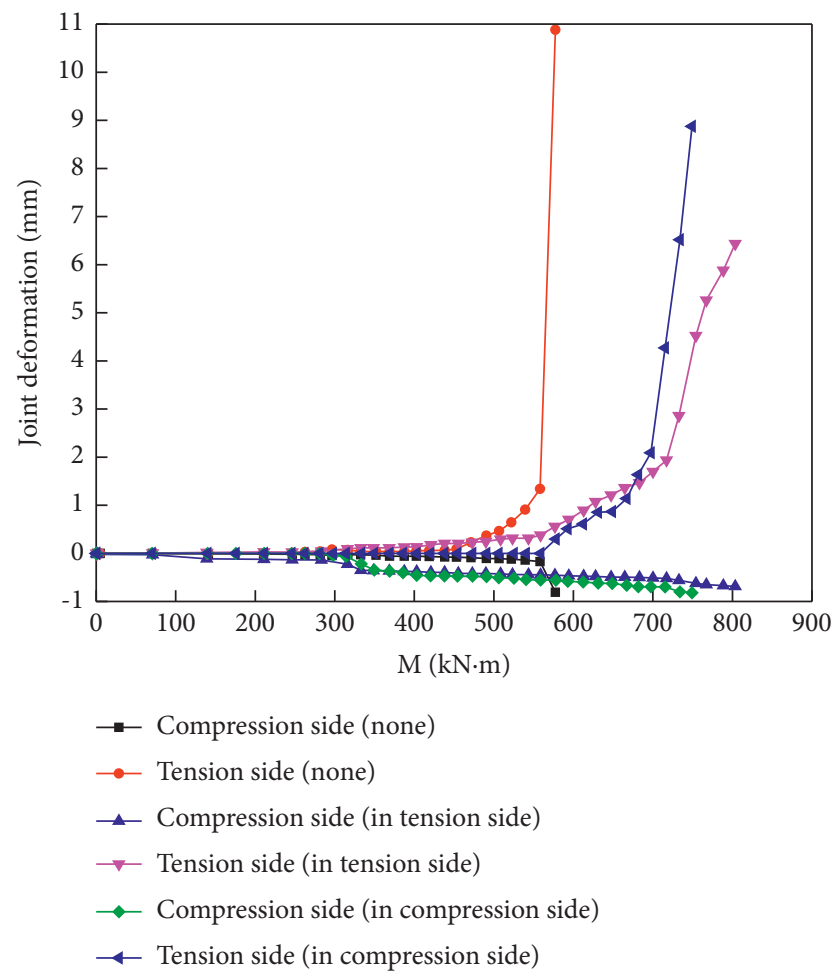

Figure 15: Deformation development of different double-tenon joints (axial force $1000 \mathrm{kN}$ ). additional tension device has larger ultimate deformation on the tensions side

(3) An inflection point of a significant increase appears in the later stage of the joint without an auxiliary pretightening device on the compression side, while this point of the joint with an external additional device is not obvious

(4) Before a sudden increase in the deformation on the tension side, the joint with an auxiliary pretightening device on the tension side experiences two stages: almost constant and linear increase. The auxiliary pretightening device of the joint with an auxiliary pretightening device on the compression side can balance and control the deformation effect very well in the early stage, and slow and linear changing occurs in almost constant and linear increase these two stages. After the inflection point is reached, it is sharply increased to the damage level, and the slope of sharp increase is greater than that of the joint with an auxiliary pretightening device on the tension side. At this inflection point, the joint with an auxiliary pretightening device on the tension side is close to the joint on the compression side under $1000 \mathrm{kN}$

From the perspective of the resistance moment:

(1) When these three types of joints do not exceed the resistance moment $(471.5 \mathrm{kN} \cdot \mathrm{m})$, the joint deformation on the tension side is almost zero, and after the loading exceeds the resistance moment, the deformation of the joint without an auxiliary pretightening device starts increasing gradually, and subsequently, the deformation sharply increases, and the curve variation is relatively steep

(2) With regard to the joint with an auxiliary pretightening device, after the loading exceeds the resistance moment, the stage where deformation is almost zero becomes longer due to the existence of auxiliary pretightening device and boss

(3) With regard to the joint with an auxiliary pretightening device on the compression side, the inflection point of a gradual increase in the deformation is the last one since the auxiliary pretightening device functions in the early stage of loading, but the curve variation is steeper than that of the auxiliary pretightening device in the tension side

(4) With regard to the joint with an auxiliary pretightening device on the tension side, the auxiliary pretightening device in the late bearing stage plays a role in controlling an increase in deformation, and the curve is relatively smooth and round compared with those of the first two types of joints

The development curves of joint deformation of singletenon joint and double-tenon joint under the axial force of $2,000 \mathrm{kN}$ per linear meter are shown in Figure 16. It can be 


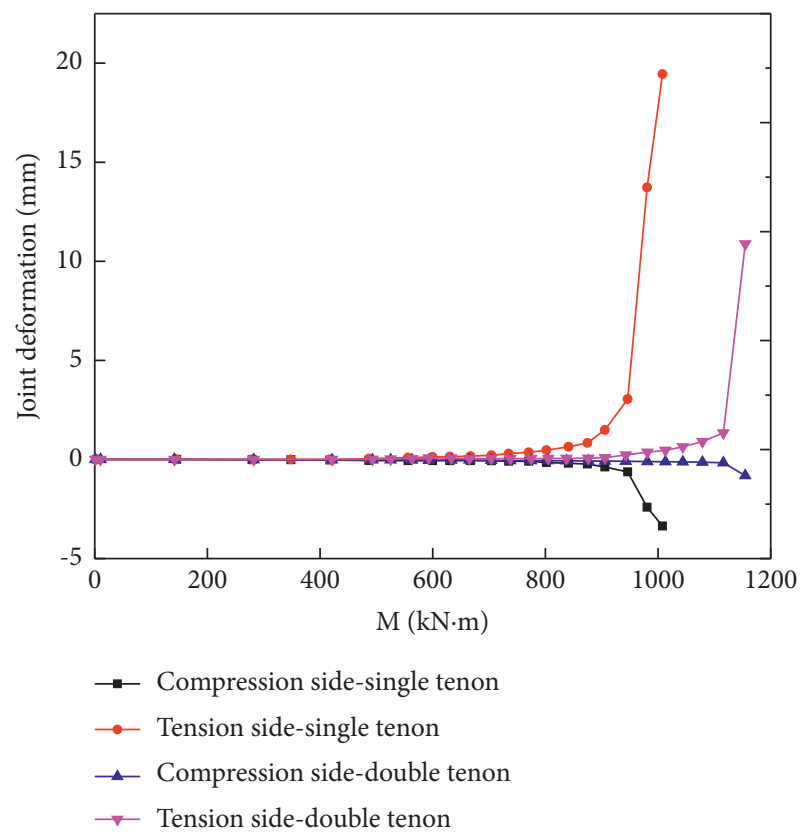

FIGURE 16: Comparison of joint deformation for single-tenon and double-tenon joints.

seen from the diagram that the joint deformation of singletenon joint and double-tenon joint experiences four stages respectively, i.e., linear variation stage, quasi-linear variation stage, nonlinear variation stage, and rapid increase stage, and under the same axial force, various stages of the doubletenon joint move rearward compared with those of the single-tenon joint, and the ultimate bearing capacity is increased; compared with the double-tenon joint, the singletenon joint has larger ultimate deformation on both the tension side and the compression side.

Furthermore, it is obvious that, after the joint starts being deformed, the deformation of the single-tenon joint is greater than that of the single-tenon joint under the same bending moment, and it can be easily seen from the curve inflection points in Figures 16 and 17 that the deformation of the single-tenon joint is greater than that of the doubletenon joint; that is to say, the deformability of the singletenon joint is higher than that of the double-tenon joint.

\section{Results of Numerical Analysis of Finite Elements}

The finite element software (ABAQUS) is used to create a grouted long single-tenon joint model having the same size, structure, material parameters, and boundary conditions as the test (Figure 18), and the model is poured with the modified epoxy resin grout and is designed as per grouting range (b), and then the simulation analysis of the loading test are conducted under the axial forces of $500 \mathrm{kN}$ and $1,600 \mathrm{kN}$. And, the concrete damaged plasticity model is selected for C50 concrete, and HRB400 parameters are adopted for rebars and auxiliary pretightening device; it can be seen from the joint experiment failure modes [14-16] that the there is no crack at the epoxy resin bonding of the joint surface.

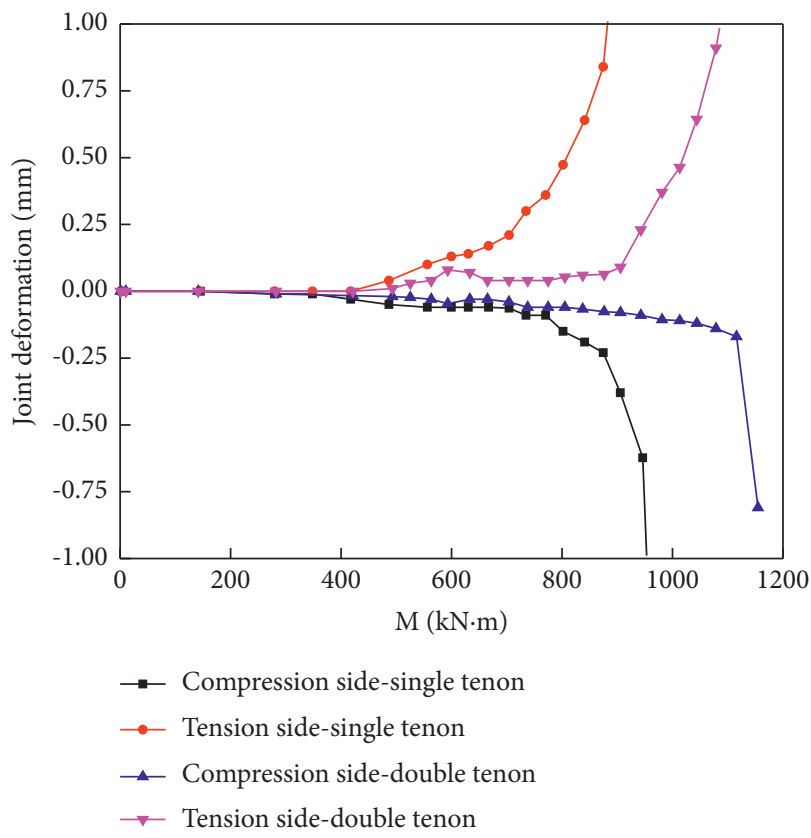

FIGURE 17: Comparison of joint deformation for single-tenon and double-tenon joints (local zoom).

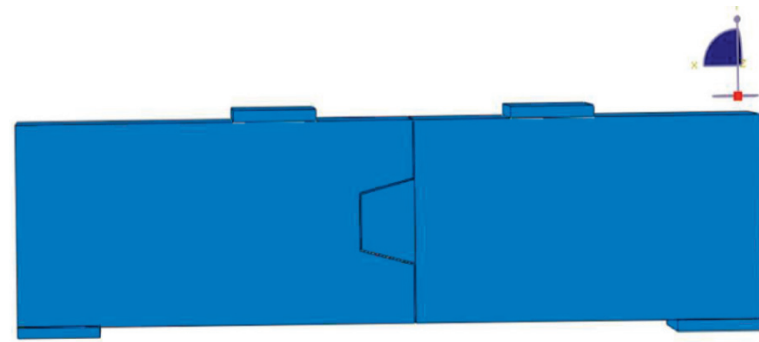

$\mathrm{x}$

FIGURE 18: Calculated model of long grouted single mortise-tenon joint.

Therefore, the epoxy resin on the joint grouting section is defined as an elastic deformation body which is separately bound to the left and right faces contacting tenon and mortise.

The comparison between calculated results and experimental results of the tension side joint deformation is extracted (Figure 19). It can be seen from the diagram that the deformation development process of theoretical calculation and test results is basically consistent, both experiencing the following stages: linear variation stage $\longrightarrow$ quasi-linear variation stage $\longrightarrow$ nonlinear variation stage $\longrightarrow$ stage of sharp increase in deformation until structural damage; the tenon crack penetration corresponds to linear variation stage + quasi-linear variation stage, while the structural crack penetration occurs in the instability damage stage. In addition, as the axial force increases, the joint deformation of the test specimen under the same bending moment becomes smaller, the curve inflection point moves rearward, and the 


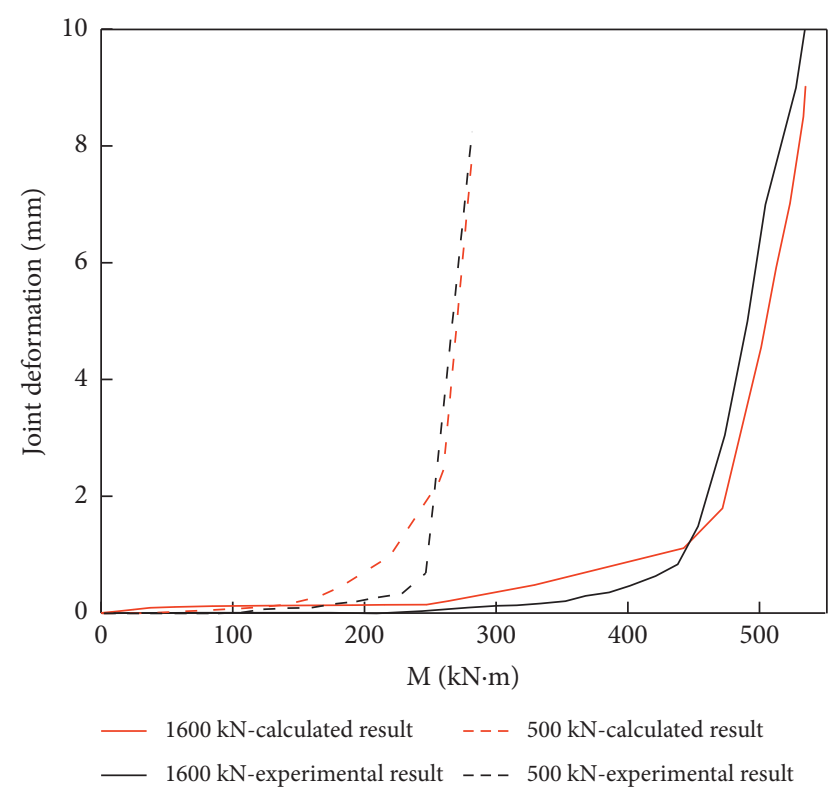

FIGURE 19: Comparison of joint deformation for calculated results and experimental results.

maximum ultimate flexural capacity becomes larger, so an increase in the axial force enhances the resistance moment of joints and contributes to the improvement of deformation resistance of joints.

\section{Site Monitoring Results}

This research monitors the joint deformation throughout the overall construction process of the Changchun prefabricated metro station (West Ring Road Station) from segmental ring erection, backfilling of topsoil upon completion of the station, and water-level recovery, and maintains statistics of $\mathrm{BC}$ joint deformation in the overall construction process (including deformation on both the tension side and the compression side), as shown in Figure 20. Obviously, the joint deformation is very small during the whole construction process, and there is sufficient safety margin from the design check line [23].

\section{Analysis of the Grouting Joint Deformation Stages}

It can be seen from the summary of experimental values of the joint deformation curve and calculated values of finite elements in different cases that the joint deformation curve mainly experiences the following four stages: linear variation stage $\longrightarrow$ quasi-linear variation stage $\longrightarrow$ nonlinear variation stage $\longrightarrow$ stage of sharp increase in deformation until structural damage, which is exactly consistent with the four stages of the bearing characteristics curve of the grouted mortise-tenon joints $[5,15,23]$.

By taking as an example the test in which the modified epoxy resin is poured within the grouting range $b$ under the axial force of $1600 \mathrm{kN}$, various stages of the joint deformation of grouted long single-tenon joints are analyzed (see

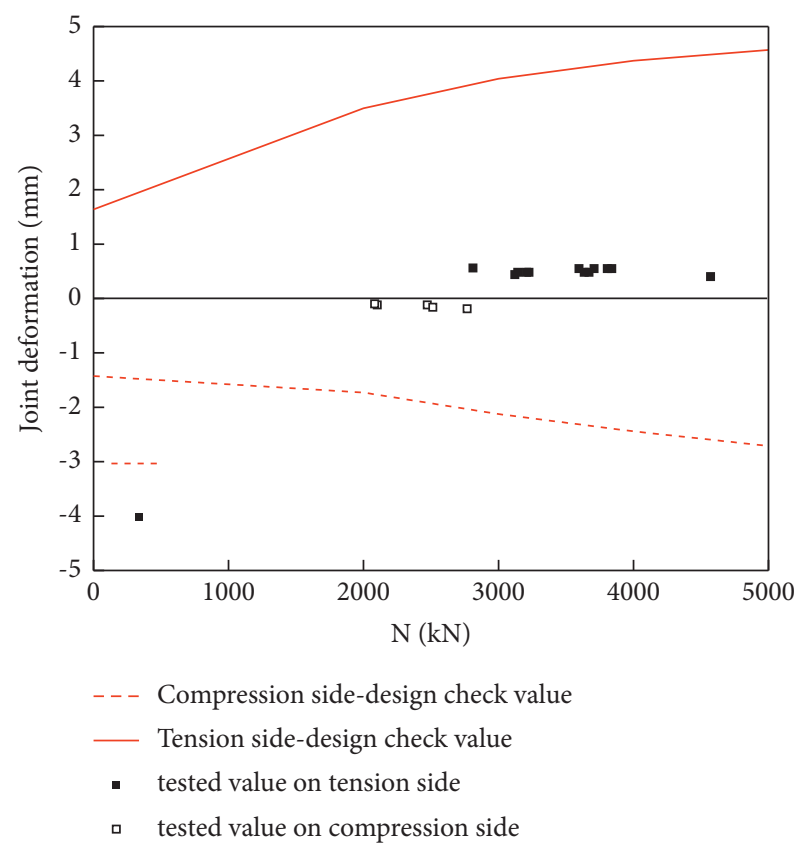

Figure 20: Deformation envelope of joint BC.

Figure 21). Stage I $(0-315 \mathrm{kN} \cdot \mathrm{m})$ of joint deformation represents the linear stage, in which the resistance moment of cross section dominates, and before the loading reaches the resistance moment, the deformation on both the tension side and the compression side is extremely small, which means there is almost no deformation; Stage II $(315 \mathrm{kN} \cdot \mathrm{m} \sim 385 \mathrm{kN} \cdot \mathrm{m})$ represents the quasi-linear stage, in which the curve slope is relatively small and a combination of resistance moment and tenon embedding dominates; Stage III $(385 \mathrm{kN} \cdot \mathrm{m} \sim 437 \mathrm{kN} \cdot \mathrm{m})$ represents the nonlinear stage, in which the joint deformation starts increasing and the growth rate shows the nonlinear trend, the overall deformation on the tension side is relatively small and is kept within $3 \mathrm{~mm}$, and compared with the first two stages, the deformation on the compression side is slightly increased; Stage IV ( $437 \mathrm{kN} \cdot \mathrm{m} \sim$ bearing limit): as loading continues, the joint will be weakened after the tenon crack penetration in this stage occurs and then enters the failure and structural damage stage, and deformation is sharply increased. After the structural crack penetration occurs, the joint will enter the structural damage state quickly, and a slight increase in the bending moment on the tension side or the compression side will cause a sharp increase in the deformation, and the deformation on the tension side will rocket to $20 \mathrm{~mm}$ very soon.

The joint corner of the test specimen is calculated and the relationship between the corner and the bearing stage is extracted (as shown in Figure 22), illustrating that in the linear stage where the resistance moment of cross section dominates, the amount of rotation of the joint slowly increases with an increase in the bending moment, and the overall amount of rotation is very small; in Stage II where the bending resistance of the tenon dominates, the amount of joint rotation is significantly higher than that in Stage I, but the overall amount of rotation is still small; after tenon crack 


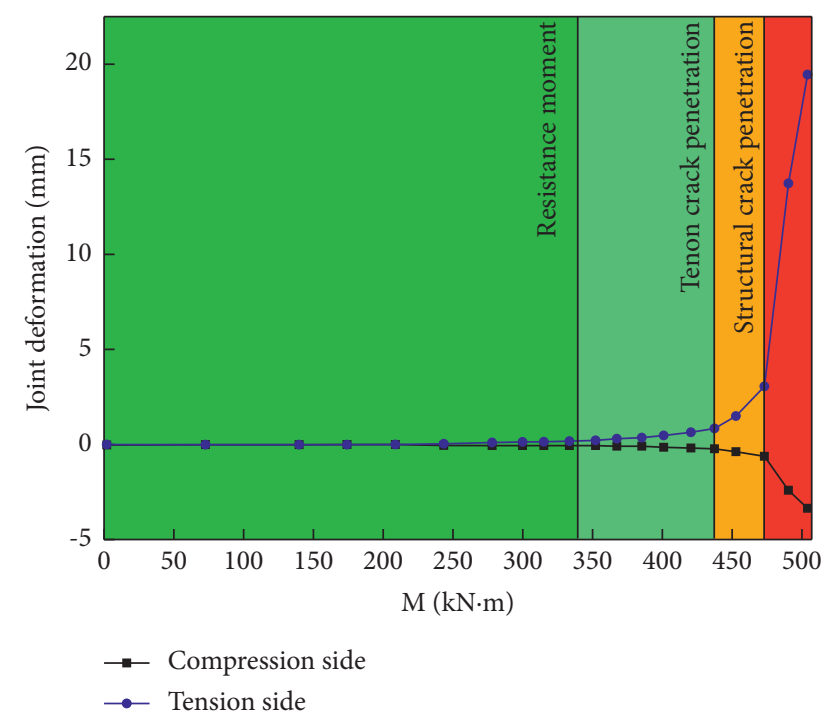

FIgURE 21: Bearing stage of joint deformation $(1600 \mathrm{kN})$.

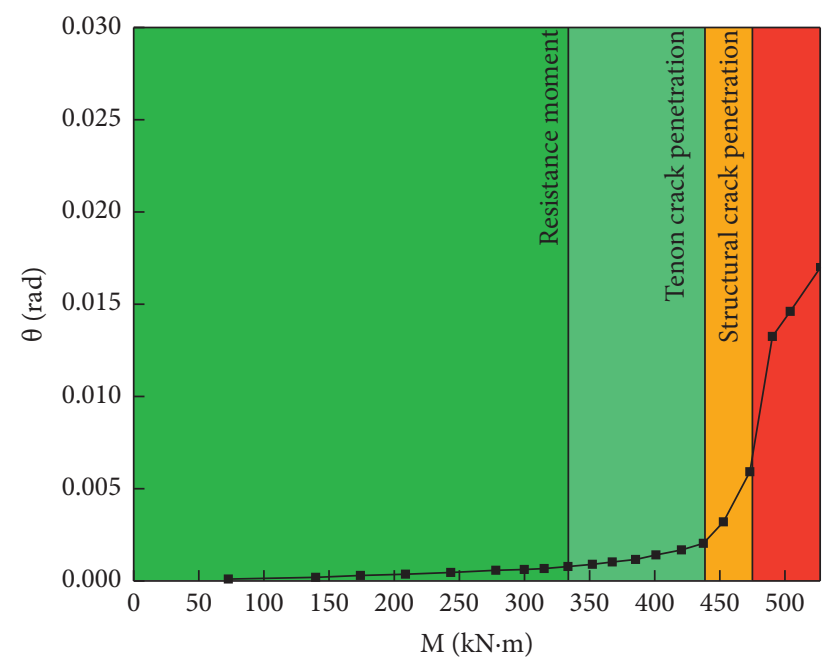

Figure 22: Bearing stage of joint deformation (1600 kN).

penetration, the amount of rotation is quickly increased and the joint is significantly weakened; after structural crack penetration, the amount of rotation is suddenly increased, and the joint enters the state of bearing capacity loss quickly.

In conclusion, the law of various stages of joint deformation of grouted mortise-tenon joints is summarized: the joint deformation enters the linear stage first, where the resistance moment of cross section dominates, and the linear section is the longest one, accounting for over $50 \%$; subsequently, it enters the quasi-linear stage, where the bending resistance of the tenon dominates, but the joint deformation is still small; after the tension side tenon crack penetration occurs on the single-tenon joint/double-tenon joint, the resistance of the tenon structure will become weak or disappears, resulting in an increase in the curve slope, and after deformation enters the nonlinear section with a higher slope, the growth rate of joint deformation will be obviously increased; after structural crack penetration, deformation will enter the sharp increase stage.

\section{Conclusion and Recommendation}

This paper analyzes and researches the law of the joint deformation of grouted mortise-tenon joints in an all-round way through the $1: 1$ prototype loading experiment and the numerical analysis of finite elements as well as the comparison of site monitoring results with test results and draws the following conclusions:

(1) Four stages are undergone by joint deformation: linear stage under the resistance moment (Stage I) $\longrightarrow$ quasi-linear stage under a combination of resistance moment and tenon embedding (Stage II) $\longrightarrow$ nonlinear stage of tenon crack appearance and development (Stage III) $\longrightarrow$ instability damage stage of tenon and structural crack penetration (Stage IV).

(2) With different grouting materials, there is little difference in the joint deformation, and only the failure mode slightly differs, and there is a small impact of different grouting materials on the joint deformation.

(3) Whether grouting is conducted has a large impact on the joint deformation, and the joint with no grouting will be greatly deformed due to the poor contact of connections and limit constraints, while grouting will play a very good role in limiting deformation.

(4) Due to an increase in the grouting range and axial force, the resistance moment is increased, the resistance of linear section to the bending moment is improved, the linear section becomes longer, and the injection point of joint deformation curve moves rearward. The higher the ultimate bearing capacity is, the stronger the resistance to deformation is.

(5) A combination of resistance moment and long tenon embedding plays a major role in resisting joint deformation.

(6) An auxiliary pretightening device is conducive for the control of joint deformation, which will function in the early bearing stage when it is set on the compression side and functions in the late bearing stage when it is set on the tension side.

(7) The flexural stiffness and bearing capacity of the double-tenon joint is higher than those of the singletenon joint, but the deformability is inferior to that of the single-tenon joint.

(8) From the perspective of site monitoring results, the joint deformation of the prefabricated metro station tested is extremely small during the whole construction period, and there are a considerable number of safety margins.

\section{Data Availability}

The data used to support the findings of this study are available from the corresponding author upon request.

\section{Conflicts of Interest}

The authors declare no conflicts of interest. 


\section{Authors' Contributions}

Xiuren Yang supervised the project and developed the concept and methodologies with Meiqun Huang. Fang Lin performed the experimental and theoretical studies.

\section{Acknowledgments}

This research was funded by the National Key S\&T Special Projects, grant no. 2017YFB1201104.

\section{References}

[1] L. Rozsa, "Precast concrete segment lining of the Budapest metro," Tunnels \& Tunnelling International, vol. 11, no. 10, 1979.

[2] J. H. Liu and X. Y. Hou, The History of Shield Tunneling, Shield Tunneling, China Railway Press, Beijing, China, 1991.

[3] H. Backmann and A. Steinle, Precast Concrete Structures, Ernst \& Sohn, Berlin, Germany, 2011.

[4] K. Beilasov, Q. H. Qian, and C. Z. Qi, The Essence of the Construction of Russian Underground Railway, China Railway Press, Beijing, China, 2012.

[5] X. Yang and F. Lin, "Prefabrication technology for underground metro station structure," Tunnelling and Underground Space Technology, vol. 108, Article ID 103717, 2021.

[6] X. Yang, Z. Shi, and F. Lin, "Influence of geometrical parameters on performance of grouted mortise and tenon joints for application in prefabricated underground structures," Advances in Civil Engineering, vol. 2019, Article ID 3747982, 14 pages, 2019.

[7] C. Gong, W. Ding, K. M. Mosalam, S. Günay, and K. Soga, "Comparison of the structural behavior of reinforced concrete and steel fiber reinforced concrete tunnel segmental joints," Tunnelling and Underground Space Technology, vol. 68, pp. 38-57, 2017.

[8] W. Ding, Y. Gong, Y. Qiao, and C. Gong, "Experimental investigation on mechanical behavior of segmental joint under combined loading of compression-bending-shear," Tunnelling and Underground Space Technology, vol. 98, Article ID 103346, 2020.

[9] W. Ding, C. Gong, K. M. Mosalam, and K. Soga, "Development and application of the integrated sealant test apparatus for sealing gaskets in tunnel segmental joints," Tunnelling and Underground Space Technology, vol. 63, pp. 54-68, 2017.

[10] M. Lei, B. Zhu, C. Gong, W. Ding, and L. Liu, "Sealing performance of a precast tunnel gasketed joint under high hydrostatic pressures: site investigation and detailed numerical modeling," Tunnelling and Underground Space Technology, vol. 115, Article ID 104082, 2021.

[11] C. Gong, W. Ding, K. Soga, and K. M. Mosalam, "Failure mechanism of joint waterproofing in precast segmental tunnel linings," Tunnelling and Underground Space Technology, vol. 84, pp. 334-352, 2019.

[12] J. Han, D. Liu, Y. Guan et al., "Study on shear behavior and damage constitutive model of tendon-grout interface," Construction and Building Materials, vol. 320, Article ID 126223, 2022.

[13] X. R. Yang, M. Q. Huang, and F. Lin, "Research strategies on new prefabricated technology for underground metro stations," Urban Rail Transit, vol. 5, pp. 1-10, 2019.

[14] X. Yang, Z. Shi, and F. Lin, "Research on shear capacity and checking method of MT.G-joint for application in prefabricated underground structures," Advances in Materials Science and Engineering, vol. 2019, Article ID 4065301, 12 pages, 2019.

[15] X. Yang, F. Lin, and M. Huang, "Experimental research on bending bearing capability of grouted double mortise-tenon joint for prefabricated metro station structure," Advances in Civil Engineering, vol. 2021, Article ID 6635409, 14 pages, 2021.

[16] X. Yang, F. Lin, and M. Huang, "Experimental analysis of bending stiffness characteristics of grouted double mortisetenon joint for prefabricated metro station structure," $A d-$ vances in Civil Engineering, vol. 2021, Article ID 9958436, 13 pages, 2021

[17] J. S. Chen and H. O. Mo, "Three-dimensional fem analysis on flexural rigidity of segment joints in shield tunnel," Journal of the China Railway Society, vol. 04, pp. 87-91, 2009.

[18] L. T. Wu, "FEM analysis on mechanical behaviors of segment joints of shield tunnel," Doctoral Dissertation, Southwest Jiaotong University, Chengdu, China, 2005.

[19] D. Y. Zeng, "Numerical simulation of segment joint bending stiffness of metro shield tunnel," Journal of Southwest Jiaotong University, vol. 39, no. 6, p. 744, 2004.

[20] B. Tvede-Jensen, M. Faurschou, and T. Kasper, "A modelling approach for joint rotations of segmental concrete tunnel linings," Tunnelling and Underground Space Technology, vol. 67, pp. 61-67, 2017.

[21] X. R. Yang, M. Q. Huang, and F. Lin, "Experimental method of grouted mortise-tenon joint for prefabricated metro station structure," Urban Rapid Rail Transit, vol. 32, no. 5, p. 83, 2019.

[22] X. R. Yang, M. Q. Huang, and F. Lin, "Research on bending resistance characteristics of grouted mortise-tenon joint for prefabricated metro station structure," China Civil Engineering Journal, vol. 53, no. 02, p. 33, 2020.

[23] X. R. Yang, M. Q. Huang, and F. Lin, "Experimental research on flexural bearing capability of short grouted single mortisetenon joint for prefabricated metro station structure," China Civil Engineering Journal, vol. 53, no. 05, p. 57, 2020. 